\title{
Performance Characteristics of n-Butanol-Diesel Fuel Blend Fired in a Turbo-Charged Compression Ignition Engine
}

\author{
Lennox Siwale ${ }^{1}$, Lukács Kristóf ${ }^{2}$, Torok Adam², Akos Bereczky ${ }^{2}$, Antal Penninger², \\ Makame Mbarawa ${ }^{3}$, Kolesnikov Andrei ${ }^{1}$ \\ ${ }^{1}$ Department of Mechanical Engineering, Tshwane University of Technology, Private Bag X680, Pretoria, South Africa; ${ }^{2}$ Department \\ of Energy Engineering, Budapest University of Technology and Economics, Budapest, Hungary; ${ }^{3}$ Ministry of Communication, \\ Science and Technology, United Republic of Tanzania Department of Energy, Dar-es-Salaam, United Republic of Tanzania. \\ Email: zumbe.siw@gmail.com, kristof.lukacs@gmail.com, atorok@kgazd.bme.hu, bereczky@energia.bme.hu, \\ penninger@energia.bme.hu, makame.mbarawa@gmail.com, KolesnikovA@tut.ac.za
}

Received October 2013

\begin{abstract}
In this study, n-butanol-diesel blends were burned in a turbo-charged, direct injection diesel engine where the brake thermal efficiency, (BTE) or brake specific fuel consumption, (BSFC) was compared with that of ethanol-diesel or methanol-diesel blends in another study by other authors. The test blends used were B5, B10 and B20 (where B5 is 5\% n-butanol by volume and 95\% diesel fuel-DF). In this study, the BTE was higher and the BSFC improved more than in the other study. Because of improved BTE with increasing brake mean effective pressure, BMEP, the BSFC reduced, however the increased shared volume of n-butanol in DF increased BSFC. Adding n-butanol in DF slightly derated the torque, brake power output with increasing speed, and caused a fall in exhaust gas temperatures, (EGT) which improves the volumetric efficiency and reduces compression work. Therefore, a small-shared volume of n-butanol in DF fired in a turbo-charged diesel engine performs better in terms of BTE and BSFC than that of ethanol or methanol blending in DF.
\end{abstract}

Keywords: Brake Specific Fuel Consumption; Brake Thermal Efficiency; Exhaust Gas Temperature; n-Butanol/Diesel

\section{Introduction}

The depletion, price uncertainty and negative effect of fossil fuels on the environment are some of the key issues that have led to a worldwide search or move towards alternative, renewable energy sources with lesser and greener emissions. The transport sector consumes about 58 percent of the primary energy consumption in the world. These fossil fuels which are becoming exhausted are the major contributors to greenhouse gas, (GHG) and climatic change [1]. The promising alternative types of fuel for petroleum oil in transportation are biofuels. These are biodegradable and do not have the same negative effect as the petroleum based fuels on the environment. Oxygenated fuels such as alcohols are one of the biofuels that have attracted research for many years because they burn cleaner than fossil fuels [2]. The advantages of alcohol as a fuel includes the following [3]. Alcohols, (a) have a lower viscosity than diesel and so improve injection, atomisation and vaporisation of the charge,(b) have less emission to the environment than diesel owing to a higher stoichiometric fuel-to-air ratio than diesel fuel (DF); (c) have a high evaporative cooling effect, resulting in cooler intake charge. This raises the volumetric efficiency and reduces compression work, besides alcohols (d) have higher laminar flame propagation than DF [4]; shorten and enhance combustion and so improve the brake thermal efficiency of the engine. Ethanol has received a wider application [5-8], although the latter possesses better qualities than ethanol. Butanol has a number of advantages over ethanol [9] such as a higher cetane number (CN), less hydrophilic; and has a higher miscibility factor in DF than ethanol [10]. Ethanol is unsuitable to use in diesel engines because of its insufficient auto ignition quality [11]. Butanol (IUPAC) is a colorless, and may irritate the eyes and skin [6]. Lubricity, intersolubility, and corrosive effects of n-butanol have been discussed in our earlier paper [12]. Researchers have carried out studies to determine the effects of n-butanol or isobutanol added to DF on performance characteristics. Rakopoulos, et al. [7] reported that the potential of butanol as a biofuel remains to be determined. The compari- 
son of properties of n-butanol, ethanol with diesel is listed in Table 1 [13,14]. Rakopoulos et al. [10] conducted experiments on a hydra engine and found a higher brake specific fuel consumption, (BSFC) at low brake mean effective pressure (BMEP) than at high BMEP for all the fuels using the blends $8 \%, 16 \%$ and $24 \%$ of n-butanol in DF. The BSFC slightly decreases with increasing load for all the fuels whereas BSFC increases with retarded main injection timing using the blends $8 \%$ and $16 \%$ of n-butanol in DF [15]. The BSFC increases when main injection timing is retarded using isobutanol, ISB15 and ISB20. The brake thermal efficiency, (BTE), was similar for all the fuels and increased with increasing BMEP using blends $8 \%$ and $16 \%$ of n-butanol in DF. The BTE slightly improved at high speed for blends up to $10 \%$ isobutanol [16]. It can be observed from the preceding cited studies that it is not quite clear which blends, whether ethanol-diesel, methanol-diesel blends or n-butanol-diesel blends would produce superior performance characteristics when burned in the compression ignition (CI) engine.

The purpose of this work was to evaluate the performance characteristics of the small volume ratios of n-bu- tanol-in DF in a diesel engine and compare results with a similar study by other authors [3] who used ethanol-diesel and methanol-diesel blends.

\section{Methods and Materials}

\subsection{Experimental Set up}

Figure 1 illustrates the engine layout for the experiments. The study was conducted on a four-cylinder piston, 1.91 L - 66 kw Turbo-Direct Injection (TDI) Volks Wagen diesel engine. This study is a continuation of the earlier study carried out by the authors on combustion [12]. A fixed electronic diesel control unit (EDU) was used to maintain stiochiometric engine performance. The diesel fuel, D2 was used as reference fuel. The test torque was varied from $100 \%, 75 \%$ and $50 \%$ to $25 \%$ of full load. The specifications of the measuring equipment used for the experiments are listed in Table 2 . The engine was ran on steady state condition for about two minutes for every measuring point before recording values. Three blends were used namely: B5, B10, or B20, and reference fuel B0 (B0 is the reference diesel, D2.

The blends were prepared on the same day using in-

Table 1. Properties of diesel, n-butanol and ethanol.

\begin{tabular}{|c|c|c|c|}
\hline Fuel properties & Diesel fuel & n-butanol $\mathrm{C}_{4} \mathrm{H}_{9} \mathrm{OH}$ & Ethanol $\mathrm{C}_{2} \mathrm{H}_{5} \mathrm{OH}$ \\
\hline Density at $20\left({ }^{\circ} \mathrm{C}, \mathrm{kg} / \mathrm{m}^{3}\right)$ & 837 & 810 & 788 \\
\hline Cetane number & 50 & $\sim 25$ & $\sim 8$ \\
\hline Lower calorific value, $\mathrm{MJ} / \mathrm{kg}$ & 43 & 33.1 & 26.8 \\
\hline Kinematic viscosity at $20^{\circ} \mathrm{C}, \mathrm{mPas}$ & $3.4^{\mathrm{a}}$ & $3.6^{\mathrm{b}}$ & $1.52^{\mathrm{b}}$ \\
\hline Boiling point ${ }^{\circ} \mathrm{C}$ & $180-360$ & 118 & 78 \\
\hline Latent heat of evaporation, $\mathrm{kJ} / \mathrm{kg}$ & 250 & 585 & 840 \\
\hline Stoichiometric air-fuel ratio & 15.0 & 11.2 & 9.0 \\
\hline Molecular weight & 170 & 74 & 46 \\
\hline Source $[13,14]$ & & & \\
\hline
\end{tabular}

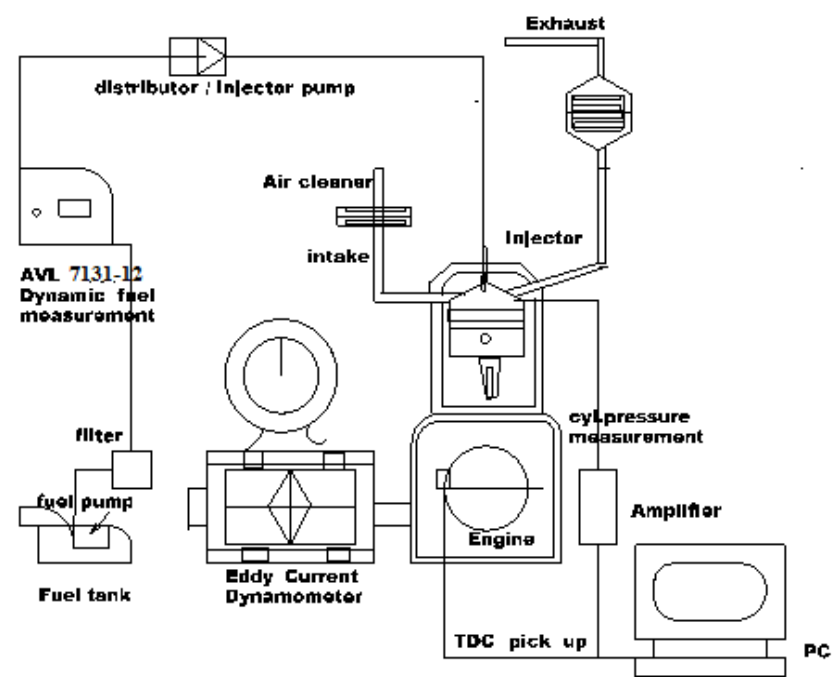

Figure 1. Schematic diagram of engine arrangement and set up for data acquisition. 
Table 2. Data measuring equipment.

\begin{tabular}{cc}
\hline Eddy current dynamometer & Type: FE350s-BORGHI and SAUERI \\
\hline Pressure transducer & Type: KISTLER KIAG 600 \\
TDC and crank angle speed pick up & Type: OPTICAL ENCODER HENGSTLER RI 32-0/1024.ER.14KA \\
Thermocouple & Type K \\
Fuel measurement & Type: AVL 7131-12 \\
\hline
\end{tabular}

tank method with standard laboratory glassware. Operating the engine for 20 to 30 minutes using the reference fuel (D2) warmed it up. The initial fuel in the tank and delivery system was nearly emptied before a new test fuel was fed into the fuel tank. The engine was ran on high load for a short period in order to speed up the removal of the fuel in the fuel delivery lines. The engine was ran using the test blend for another 20 minutes in order to stabilize the engine on the new test fuel.

The fuel mass-flow rate was measured using the AVL 7131-12 dynamic fuel consumption measuring equipment. The fuel balance works on the gravimetric measuring principle. This instrument enables the highest temperature stability of the fuel conditioning system with measuring accuracy of $0.12 \%$; including self-calibration according to ISO 9001. Fuel is supplied to the engine from a measuring vessel the weight of which is continuously measured.

The torque was measured by a Borghi and Saveri eddy current dynamometer, type FE-350S and the crank angle and speed were measured by an encoder or sensor (placed on the dynamometer shaft connected to the TDI diesel engine). The engine parameters are listed in Table 3.

\subsection{Materials}

The n-butanol fuel was manufactured by VWR Prolabo (BDH), of $99.99 \%$ purity, density of $809 \mathrm{~kg} / \mathrm{m}^{3}\left(20^{\circ} \mathrm{C}\right)$, molecular formula: $\mathrm{C}_{4} \mathrm{H}_{9} \mathrm{OH}$, molecular mass: MW 74.12 $\mathrm{kg} / \mathrm{kmol}$, boiling point: $118^{\circ} \mathrm{C}$ (at $101.3 \mathrm{kPa}$ ), melting point: $-89.8^{\circ} \mathrm{C}$, and flash point: $30^{\circ} \mathrm{C}$. The type of $\mathrm{DF}$ used for the experiments was: D2, standard EN 590, CN: 51 , sulphur content of $\leq 10 \mathrm{mg} / \mathrm{kg}$; water content of $\leq 200$ $\mathrm{mg} / \mathrm{kg}$; and kinematic viscosity of 2.00 to $4.5\left(\mathrm{~mm}^{2} / \mathrm{s}\right)$ at $40^{\circ} \mathrm{C}$, specific density at $15^{\circ} \mathrm{C}, \geq 0.82$; and flash point of $>55^{\circ} \mathrm{C}$. The reference fuel was DF, (D2).

\section{Results and Discussion}

A study was conducted where a small-shared volume of ethanol with diesel (E5 and E10) was compared with methanol/diesel blends: M5, M10 (M5 is 5\% by volume of methanol in DF). The test was based on a naturally aspirated engine with bore size of $98 \mathrm{~mm}$ and stroke 100 $\mathrm{mm}$ and compression ratio 17:1. [3]. The cited study is hence designated as study A.

Figure 2 illustrates the effect of blends on BSFC. It is well established that the lower energy content of the al-
Table 3. Engine parameters.

\begin{tabular}{cc}
\hline Bore & $79.5[\mathrm{~mm}]$ \\
Stroke & $95.5[\mathrm{~mm}]$ \\
Compression ratio & $19.5-$ \\
Maximum Torque & $202[\mathrm{Nm}] / 1800[\mathrm{rpm}]$ \\
Maximum power & $66[\mathrm{~kW}] / 4000[\mathrm{rpm}]$ \\
Fuel system: & \\
Injector pump & Distributor-type \\
& (Bosh VP37) \\
Combustion chamber & Bowl in piston \\
Injector type andpressure & 5 hole, $180[$ bars $]$ \\
\hline
\end{tabular}

cohols increases the BSFC. Therefore, alcohols having a higher heating value than others will have a lower BSFC. For this reason, the minimum BSFC in study A was 298 $\mathrm{g} / \mathrm{kwh}$ compared with $237 \mathrm{~g} / \mathrm{kwh}$ in the current study where n-biutanol/diesel blends were used at 1500 RPM.

Figures 3(a) and (b) depict the BTE at speeds 1500 and at 3000 RPM respectively. The oxygenated fuels such as alcohols are well known to improve combustion when blended with DF because of the oxygen atoms attached to their structural composition. In order to determine which blends have a better performance with regards to thermal efficiency, the BTE between study A and this study were compared. The value of BTE in study A was in the range of: 0.22 to 0.28 for the speed range of 1000 to 1600 RPM. In the current study, the BTE fell into the range: 0.25 to 0.35 with $1500 \mathrm{RPM}$.

The higher BTE of n-butanol/diesel blends is attributed to their higher $\mathrm{CN}$ than ethanol/or methanol/diesel blends. In the current study, BTE increased during the testing of the fuels with BMEP. The irregularity observed on 3 and 6 bars, BMEP with 3000 RPM could probably be attributed to the slower evaporation of the n-butanol blends as a result of their lower CN than DF. The constant BTE (see Figure 3) at a particular BMEP does not correlate with the BSFC at the same BMEP (see Figure 2) with respect to the trends, according to this formula: BTE is 1/(BSFC*LHV). This can be explained as follows. The energy content, that is the Lower heating value, (LHV) of the blend decreases with the increasing fraction by volume $(\mathrm{v} / \mathrm{v})$ of $n$-butanol in DF. This causes the fuelmass flow to increase the BSFC. Thus, the two effects compensate each other and maintain the same BTE. Improvement of BTE can be as a result of better atomisation of the blend, and effects on friction [17]. Atomisation of a fuel is affected by the fuel's surface tension, 
(a)

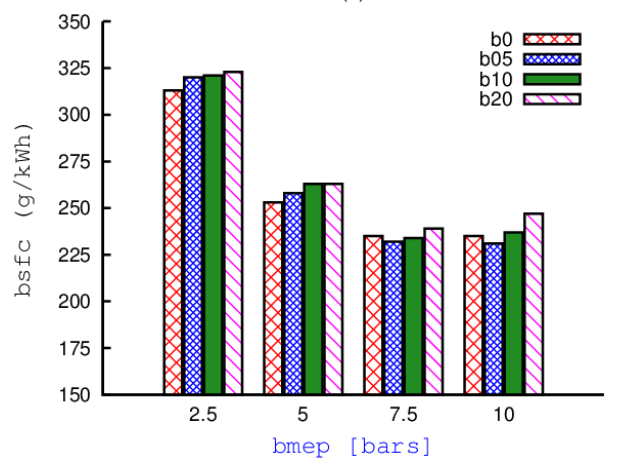

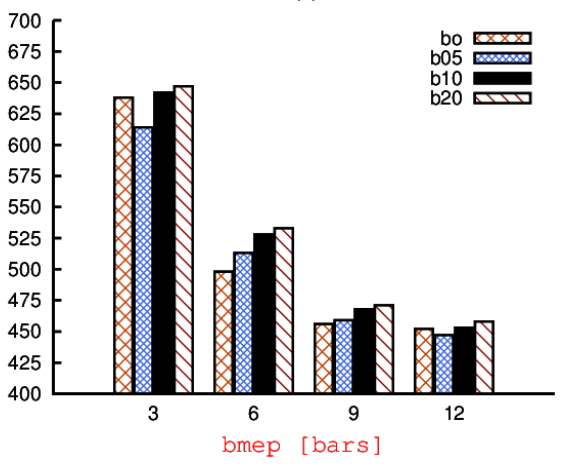

Figure 2. Brake specific fuel consumption (BSFC) vs. BMEP (a) at $1500 \mathrm{rpm}$ (b) at $3000 \mathrm{rpm}$.

(a)

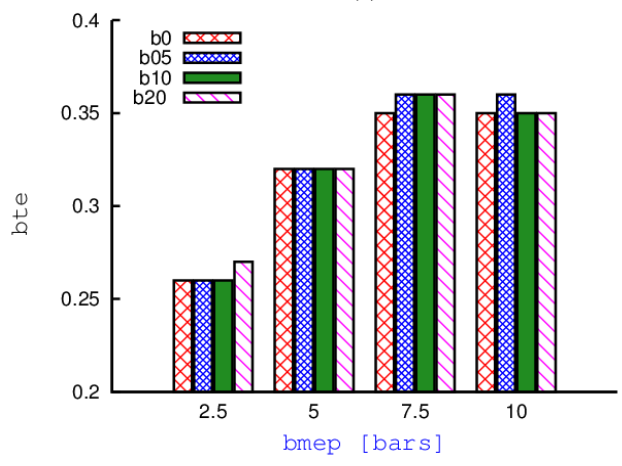

(b)

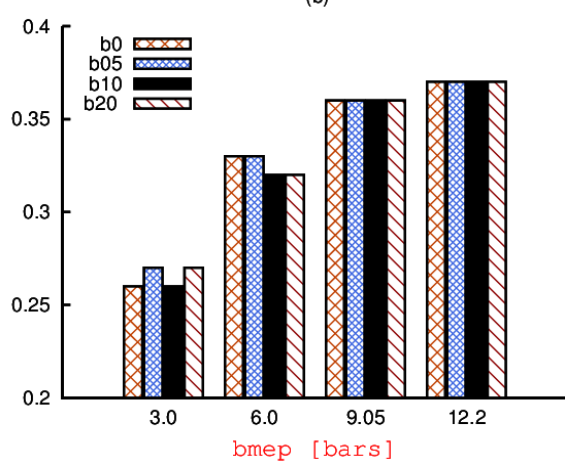

Figure 3. (a) Brake thermal efficiency (BTE) vs BMEP (a) at $1500 \mathrm{rpm}$ (b) at $3000 \mathrm{rpm}$.

viscosity and density, jet diameter or Sauter Mean Diameter (SMD), relative velocity of the jets and its surroundings and turbulence [18]. High viscosity of the liquid fuel, leads to poor atomisation and break-up, which increases the SMD and reduces the spray angle. The droplets reaching the surface of the cylinder wall can cause dilution of the lubricating oil [18]. This can reduce the friction torque by improving the lubricity around the piston rings during the compression stroke [17]. However, the spray of oxygenated fuel presents a finer droplet, a stronger interface between the fuel spray and the surrounding gas, and a more violent vortical motion. Therefore, the viscosity of the oxygenated fuels exerts a significant effect on the improvement of atomisation behavior [19]. This action causes a slightly improved BTE.

Figure 4 depicts the effect of the blends on torque and power as the speed is increased. The lowered power and torque with engines operating on n-butanol-diesel blends is attributed to changes to the heating value (which is lower than that of pure DF) brought about by the blends.

Another contributing factor is the control system. This determines the level of the fuel-control ring position, which changes depending upon the load applied to the engine. Algorithms used for the maps of the EDC are tailored for DF. When the fuel is changed, the EDC interprets that the fuel in use is diesel if not modified. The

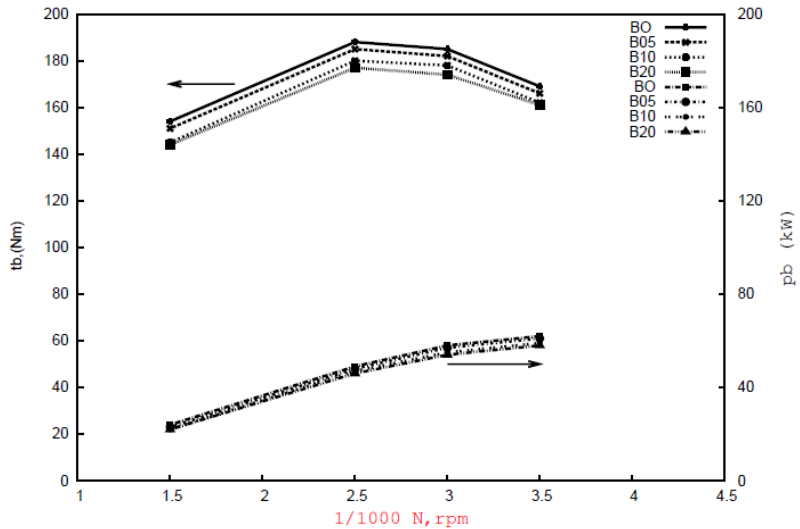

Figure 4. Torque (tb) and Brake power, (pb) vs speed.

EDC in this study was not modified. The drop in the energy content of the fuel, (due to blending) causes a fall in the power output or pressure, which is the signal mapped to the EDC. The EDC changes the fuel-control ring position to increase the mass of fuel injected into the combustion chamber. However, the fuel mass quantity delivered or the fuel-control ring level cannot be increased or raised above the reference value set for the DF. This explains why the power was de-rated with the increase of n-butanol shared volume in DF. The maximum torque and the power output are both sensitive to the speed (see 
Figure 4).

Figures 5(a) and (b) illustrate the effect on the EGT, at 1500 and 3000 RPM respectively. Whereas the load (BMEP) caused EGT to increase, blends, which have a higher heat of evaporation than DF, lowered EGT through evaporative cooling. Therefore, the EGT using DF was higher than that of the blends. The lower EGT of the blends than DF contributes to increasing the volumetric efficiency and in turn reducing compression work during the compression stroke.

Figures 6(a) and (b) illustrate the effect of the blends on manifold boost (air) pressure at 1500 and 3000 RPM. The boost (air) pressure level is a measure that helps to improve the BTE as the fuel-air ratio is reduced. Air pressure boosted in this way by the turbo-charged device at the intake side of the engine is not a parasitic work because the turbo-charged device as is well known is driven by the waste exhaust gas. Therefore, the volumetric efficiency is again improved and the compression work (parasitic work of the engine) reduced. This consequently improves the BTE of the engine.

Figure 7 illustrates the effect of all the test fuels on the injection timing or start of injection (SOI) in the crank angle degrees, (CADs) with 1500 and 3000 RPM. The injection timing was more advanced at the speed of 3000 RPM than at the speed of 1500 RPM. This was expected, owing to the reduced (CADs) that the fuel mixture was

(a)

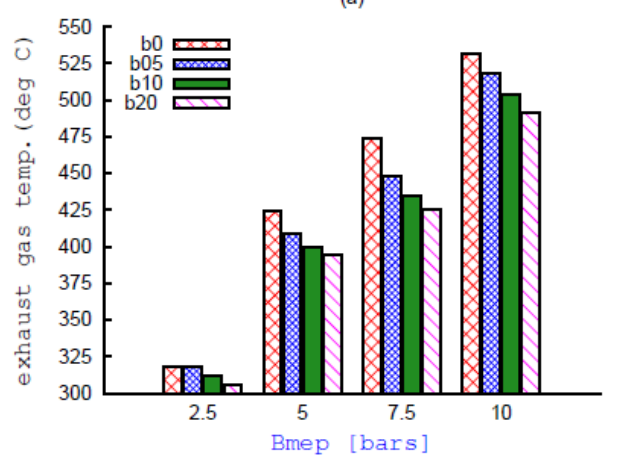

permitted to burn at high speed. However, the EDC retarded the timing of SOI on partial loads in order to match the operating conditions. The fuel-injection timings of the blends and DF controlled by the EDC for different speeds of 1500, 2500, 3000 and 3500 RPM were: $11^{\circ} 11^{\circ}, 12^{\circ}$ and $15^{\circ}$ CAD before top dead centre (BTDC) respectively.

\section{Conclusions}

The purpose of this work was to compare the performance characteristics of small fractions (v/v) of n-butanol-diesel blends fired in a turbo-charged, direct injection diesel engine with a similar study by other authors using ethanol-and methanol-diesel blends.

- The BSFC was lower and BTE was higher in our study than in the other study.

- The reduction of exhaust gas temperature (EGT) improves the volumetric efficiency, which in turn reduces the compression work during the compression stroke.

- Applying small-shared volumes of n-butanol to diesel fuel improves the BTE and BSFC requiring no engine modification compared with that of ethanol-or methanol-diesel blends. The boost pressure improves brake thermal efficiency (BTE) whereas the start of injection is retarded at low speed.

(b)

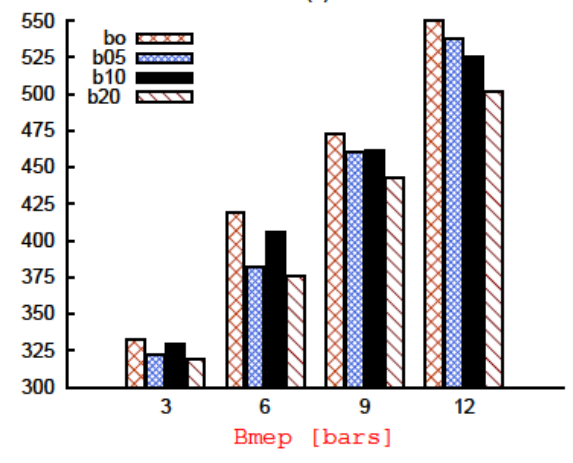

Figure 5. Exhaust gas temperature, (EGT) vs BMEP (a) at $1500 \mathrm{rpm}$ and (b) at $3000 \mathrm{rpm}$.

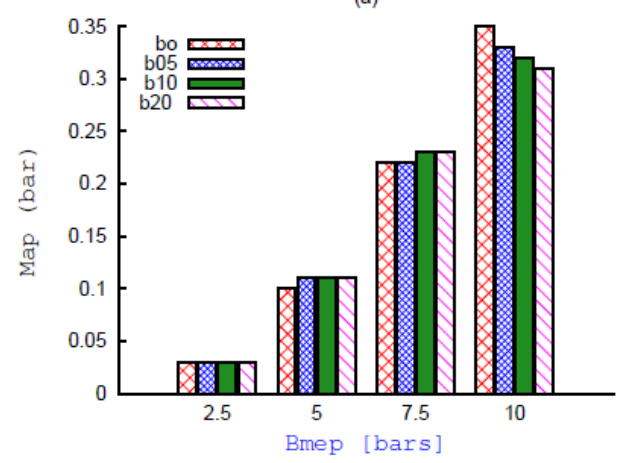

(b)

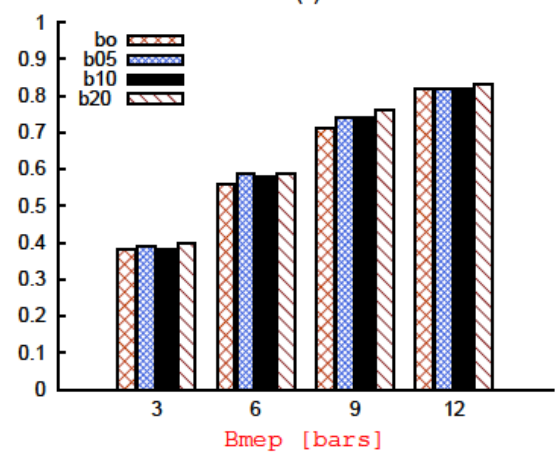

Figure 6. Boost (air) pressure vs BMEP (a) at $1500 \mathrm{rpm}$ (b) at $3000 \mathrm{rpm}$. 


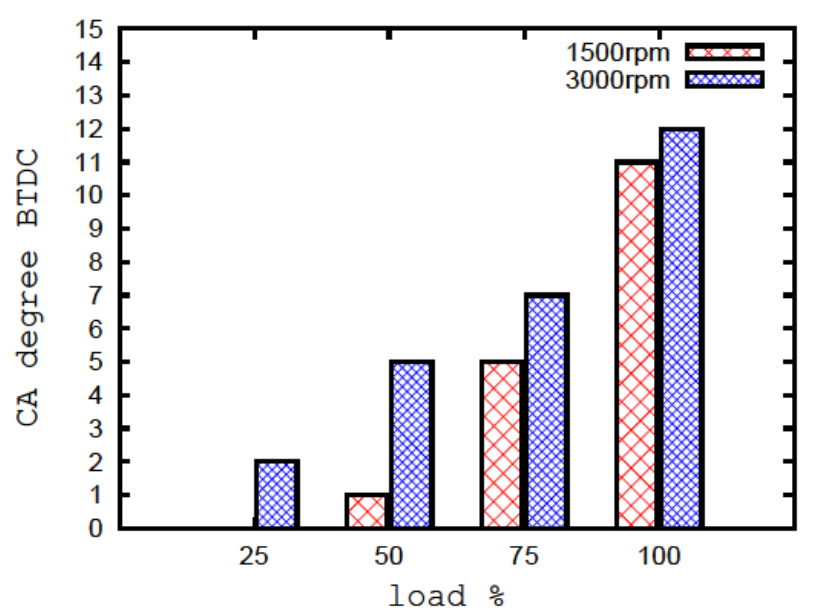

Figure 7. Crank angle advance for start of injection (SOI) timing for DF and blends at different loads and speed.

\section{Acknowledgements}

The authors wish to acknowledge and are greatly indebted for the financial support: (UID 72384 and TÉT_10-12011-0005) and facilitation by the joint research collaboration between two Universities: Tshwane University of Technology, Pretoria, South Africa and Budapest University of Technology and Economics, Budapest, Hungary, where the engine experiments were conducted in the laboratory facility, Jendrassik Gyorgy hotechnikai Laboratorium in Budapest BME.

\section{REFERENCES}

[1] P. Singh and A. Singh., "Production of Liquid Biofuels from Renewable Sources," Progress in Energy and Combustion Science, Vol. 37, 2011, pp. 52-68. http://dx.doi.org/10.1016/j.pecs.2010.01.003

[2] D. Oguzhan, "The Influence of n-Butanol/Diesel Fuel Blends Utilization on a small Diesel engine Performance and Emissions," Fuel, Vol. 90, No. 7, 2011, pp. 24672472. http://dx.doi.org/10.1016/j.fuel.2011.02.033

[3] C. Sayin, "Engine Performance and Exhaust Gas Emissions of Methanol and Ethanol-Diesel Blends," Fuel, Vol. 89, No. 11, pp. 3410-3415. http://dx.doi.org/10.1016/j.fuel.2010.02.017

[4] X. Gu, Z. Huang, S. Wu and Q. Li, "Laminar Burning Velocities and Flame Instabilities of Butanol Isomers-Air Mixtures," Combustion and Flame, Vol. 157, No. 12, 2010, pp. 2318-2325. http://dx.doi.org/10.1016/j.combustflame.2010.07.003

[5] S. Szwaja and J. D. Naber, "Combustion of n-Butanol in a Spark-Ignition IC Engine,” Fuel, Vol. 89, No. 7, 2010, pp. 1573-1582. http://dx.doi.org/10.1016/j.fuel.2009.08.043

[6] P. D’urre, "Fermentative Butanol Production Bulk Chemical and Biofuel," Annals of the New York Academy of Science, Vol. 1125, 2008, pp. 353-362. http://dx.doi.org/10.1196/annals.1419.009

[7] J. Dernotte, M. Rouselle, F. Halter and P. Seers, "Evaluation of Butanol-Gasoline Blends in a Port Fuel-Injection, Spark-Ignition Engine,” Oil Gas Science Technology. Review, Vol. 65, No. 2, 2010, pp. 345-351.

[8] M. D. M. Singliar, "Emerging Technologies for Second Generation of Biofuels,” MOL Scientific Magazine, SD and HSE special, 2008, pp. 67-80.

[9] W. Bryan, K. Kumar,Y. Zhang and J. Sung-chin., “Autoignition of n-Butanol at Elevated Pressure and Low-toIntermediate Temperature,” Combustion and Flame, 2011, Vol. 158, pp. 809-819. http://dx.doi.org/10.1016/j.combustflame.2011.02.005

[10] D. C. Rakopoulos, C. D. Rakopoulos, E. G. Giakoumis, A. M. Dimaratos and D. C. Kyritsis, "Effects of ButanolDiesel Fuel Blends on the Performance and Emissions of a High-Speed DI Diesel Engine,” Energy Conversion and Management, Vol. 51, No. 10, 2010, pp. 1989-1997. http://dx.doi.org/10.1016/j.enconman.2010.02.032

[11] C. Murat, F. Yuksel and H. Hus, "Emission Characteristics of a Converted Diesel Engine using Ethanol as Fuel," Energy for Sustainable Development, Vol. 13, 2009, pp. 250-254. http://dx.doi.org/10.1016/j.esd.2009.10.001

[12] L. Siwale, L. Kristóf, T. Adam, A. Bereczky; A. Penninger, M. Mbarawa and A. Kolesnikov, "Combustion and Emission Characteristics of n-Butanol/Diesel Fuel Blend in a Turbo-Charged Compression Ignition Engine,” Fuel, Vol. 107, No. 2013, 2013, pp. 409-418. http://dx.doi.org/10.1016/j.esd.2009.10.001

[13] Y. Liu, W. Jiao and G. Qi, "Preparation and Properties of Methanol-Diesel Oil Emulsified Fuel under High-Gravity Environment,” Renewable Energy, Vol. 36, No. 5, 2011, pp. 1463-1468.

[14] S. Pukalskas, Z. Bodanovicius, V. Makareviciene, E. Sendzikiene and P. Janulis, "The Mixture of Biobutanol and Petrol for Otto Engines,” Transport, Vol. 24, No. 4, 2009, pp. 301-307.

http://dx.doi.org/10.3846/1648-4142.2009.24.301-307

[15] D. C. Rakopoulos, C. D. Rakopoulos, D. T. Hountalas, E. C. Kakaras, E. G. Giakoumis and R. G. Papagiannakis, "Investigation of the Performance and Emissions of Bus Engine Operating on Butanol/Diesel Fuel Blends,” Fuel, Vol. 89, No. 10, pp. 2781-2790. http://dx.doi.org/10.1016/j.fuel.2010.03.047

[16] M. Yao, H. Wang, Z. Zheng and Y. Yue, "Experimental study of n-Butanol Additive and Multi-Injection on HD Diesel Engine Performance and Emissions,” Fuel, Vol. 89, No. 9, 2010, pp. 2191-2201. http://dx.doi.org/10.1016/j.fuel.2010.04.008

[17] T. Kikuchi, I. Shinichiro and N. Yoshinori, "Piston Friction Analysis Using a Direct-Injection Single-Cylinder Gasoline Engine,” Japan Society of Automotive Engineers, No. 1, 2003, pp. 53-58.

[18] R. K. Pandey, A. Rehman and R. M. Sarviya, "Impact of Alternative Fuel Properties on Fuel Spray Behaviour and Atomization," Renewable and Sustainable Energy Reviews, Vol. 16, No. 3, 2012, pp. 1762-1778. 
[19] Z. Wu, Z. Zhu and Z. Huang, “An Experimental Study on the Spray Structure of Oxygenated Fuel Using LaserBased Visualization and Particle Image Velocimetry,”
Fuel, Vol. 85, 2006, pp. 1458-1464.

http://dx.doi.org/10.1016/j.fuel.2005.12.024 